\title{
INVESTIGATION OF BATCH INTENSIVE QUENCHING PROCESSES WHEN USING HYDRODYNAMIC EMITTERS IN QUENCH TANKS
}

\author{
Nikolai Kobasko \\ Intensive Technologies Ltd \\ 68/1 Peremohy ave., Kyiv, Ukraine, 03113 \\ nkobasko@gmail.com
}

\begin{abstract}
The paper discusses patented in Ukraine a new intensive quenching IQ-2 technology based on film boiling resonance effect [1]. Namely, the paper discusses improving of the batch intensive quenching (IQ) process known as IQ-2 method by the use of hydrodynamic emitters installed in quench tanks. The hydrodynamic emitters produce oscillating waves in the quench media with the frequency of the film boiling process creating a resonance effect. Two- and three-step IQ-2 processes are considered. Specifics of the heat transfer during the IQ-2 process are presented with focusing on the first stage of quenching where film and nucleate boiling processes are taking place. Examples of production IQ-2 equipment and loads processed are also presented. Application of hydrodynamic emitters in the IQ water tanks in addition to currently used propellers is considered in details. It is shown that the proposed new method can fully eliminate the film boiling process resulting in significant reduction of part distortion during quenching. Further evaluation of the proposed method is needed for its implementation in heat treating practice.

Keywords: IQ-2 process, local film boiling, resonance effect, elimination, water flow, low distortion, smooth hardness, hydrodynamics wave emitters.
\end{abstract}

\section{Introduction}

One of the major achievements in technology of heat treating of steels was a discovery of the intensive quenching (IQ) phenomenon. The essence of the IQ phenomenon is that steel parts don't crack when quenching with a very high cooling rate, while the part distortion is lower and mechanical properties and performance characteristics are superior compared to conventional quenching in oil. During intensive quenching, a martensitic structure forms quickly and uniformly in the part surface layer creating high current surface compressive stresses, which act as a die minimizing part distortion and preventing part cracking [1-5]. Two IQ processes are currently used in heat treating practice: a batch IQ process and a single-part processing IQ method. When using the batch IQ process, known as IQ-2 method, parts are quenched in batches in IQ water tanks. When using the single-part processing IQ technique (known as IQ-3 method), parts are quenched one by one in high-velocity IQ units. This paper considers a current status of the use of the IQ-2 process in production conditions and ways of its further improvement by elimination of local film boiling which is reason for big distortion of steel parts after batch quenching [6].

\section{IQ-2 process and equipment}

The IQ-2 process is a two- or three-step quenching method. The first step of cooling takes place in an IQ water tank and is interrupted at a certain period of time when the core of the parts being quenched is still hot. The parts are cooled in the air during the second step of quenching. The part martensitic layer is self-tempered by the heat coming from the part core. If necessary, the load can be brought back into the quench tank for the completion of the quench. The modes of heat transfer during the IQ-2 processes are the following. A film boiling process followed by a nucleate boiling process takes place during the first step of the IQ-2 process. A free convection mode of heat transfer takes place when the load is cooled in the air at the second step of the IQ-2 process. A convective heat transfer takes place when the load is introduced back into the quench. Note that the film boiling process is a major reason for part distortion and, in some cases, part cracking. A sporadic and not controllable film boiling process may result in a non-uniform formation of the martensitic structure throughout the part surface causing part excessive distortion. To minimize 
the duration of the film boiling process or to eliminate it completely, a vigorous quenchant agitation and additives to water are used in production IQ water tanks (Fig. 1).

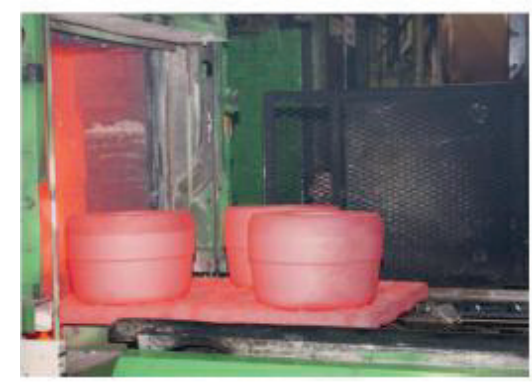

$a$

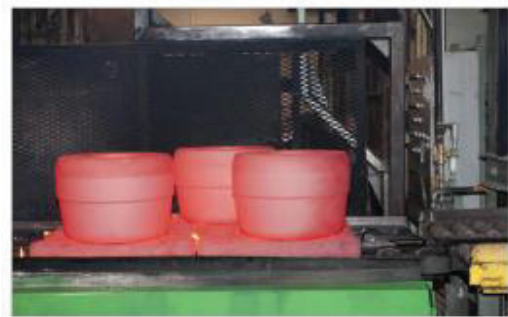

b

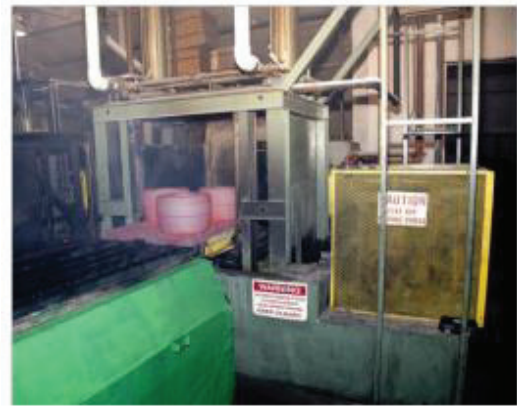

c

Fig. 1. Standalone $23 \mathrm{~m}^{3}$ IQ water tank installed across atmosphere box furnace at Akron Steel Treating Co. [7, 8]: $a$ - load is exiting the furnace; $b$-load is on the transfer cart; $c$ - load is entering the IQ tank

Two types of batch IQ equipment are used in heat treating practice: standalone IQ water tanks and IQ water tanks that are a part of integral quench atmosphere furnaces. In both types of IQ equipment, powerful propellers for providing a vigorous water agitation and water salt solution of optimal concentration are used. Fig. 1 presents a picture of the standalone $23 \mathrm{~m}^{3}$ IQ water tank installed at Akron Steel Treating Co. of Akron, Ohio, USA. The load is austenitized in an atmosphere $91 \times 91 \times 122 \mathrm{~cm}$ box furnace located across the aisle from the IQ tank. A transfer cart is used for transferring hot parts from the furnace to the quench tank. Fig. 2 present a picture of the atmosphere integral quench $91 \times 91 \times 183 \mathrm{~cm}$ furnace equipped with a $41 \mathrm{~m}^{3}$ IQ water tank and installed at Euclid Heat Treating Co. of Cleveland, Ohio, USA. The furnace is equipped with an intermediate chamber connecting the heating chamber with the IQ tank to ensure that quenchant vapor does not contaminate the furnace atmosphere. The furnace atmosphere enters the intermediate chamber through two openings in the furnace door and leaves through the vent. The IQ tank is equipped with four propellers rotated by four powerful motors and with a loading unloading mechanism that provides a very fast introduction of the load into the quench tank and removal of the load from the tank. The loading/unloading time is within about two or three seconds regardless of the load weight, which ensures a small difference in cooling times between the lower and upper layers of the load.

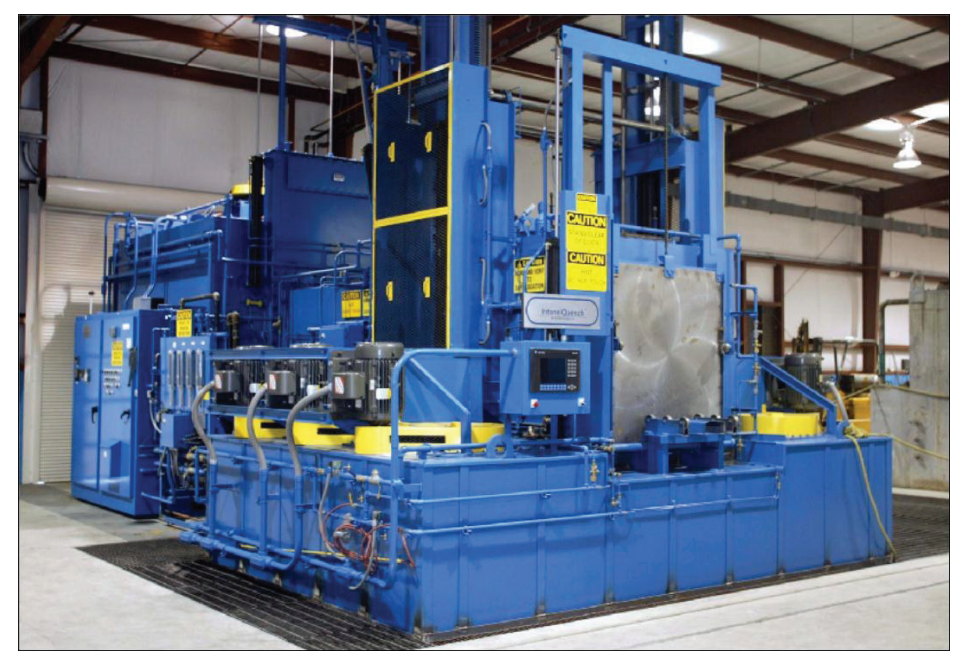

Fig. 2. Integral quench atmosphere furnace equipped with $41 \mathrm{~m}^{3} \mathrm{IQ}$ water tank built by AFC-Holcroft and installed at Euclid heat treating Co 
As an example, Fig. 3, 4 show two production loads processed in the above integral quench furnace. The first load consists of long shafts of $51 \mathrm{~mm}$ diameter and $660 \mathrm{~mm}$ length made of AISI 1040 steel. The shaft maximum distortion after IQ was $2 \mathrm{~mm}$ while the average shaft distortion was $1 \mathrm{~mm}$. This is more than 3 times less compared to the shaft distortion after conventional quenching in oil. The second load consists of forged rings of $241 \mathrm{~mm} \mathrm{OD,} 191 \mathrm{~mm}$ ID and $13 \mathrm{~mm}$ thickness made of AISI 1045 steel. The quality defects due to excessive ring distortion dropped from $18 \%$ when quenching in polymer to $1 \%$ after IQ. As seen from these examples, the IQ process significantly reduces the part distortion compared to conventional quenching in oil or polymer. The part distortion after intensive quenching can be further reduced by the full elimination of the film and local film boiling processes by the use of hydrodynamic (or resonance waves) emitters.

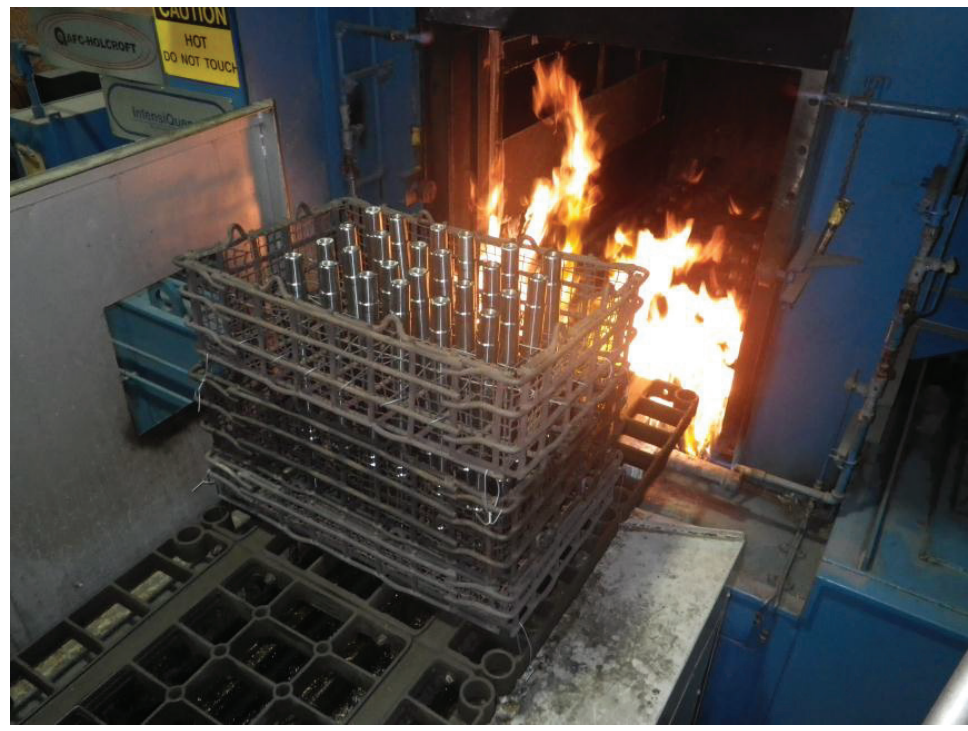

Fig. 3. Load with shafts

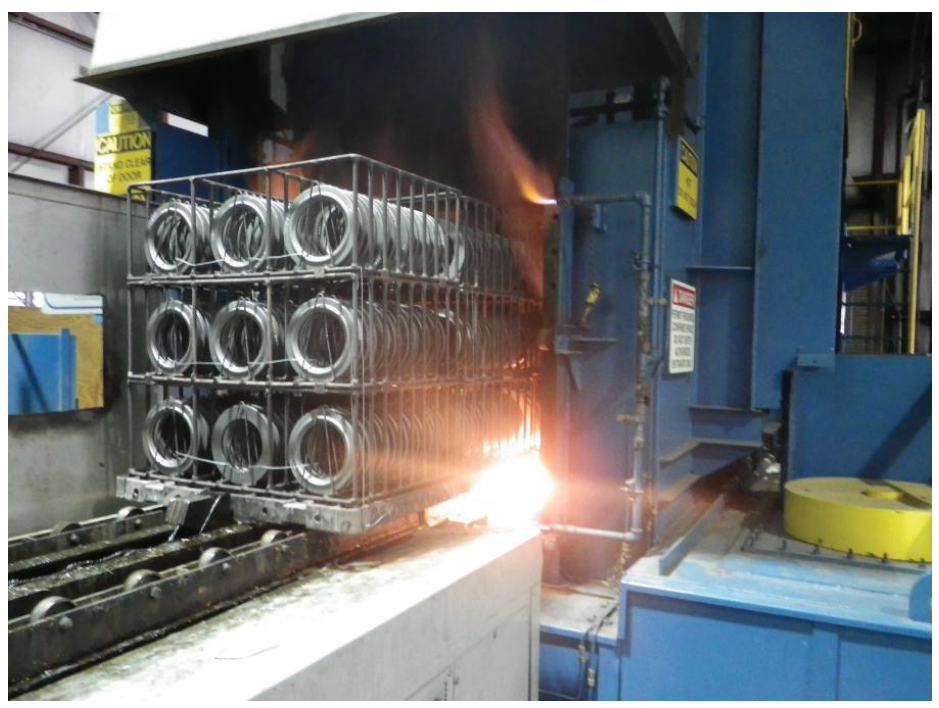

Fig. 4. Load with rings

The role of local film boiling (Fig. 5) on distortion of steel parts after batch quenching was widely discussed by authors [6]. Improvement of quality of rollers made of Dura-Bars was presented and discussed at the international conferences [7, 8]. The IQ-2 and IQ-3 processes and methods of recipes calculations are provided in publications [9-12]. 


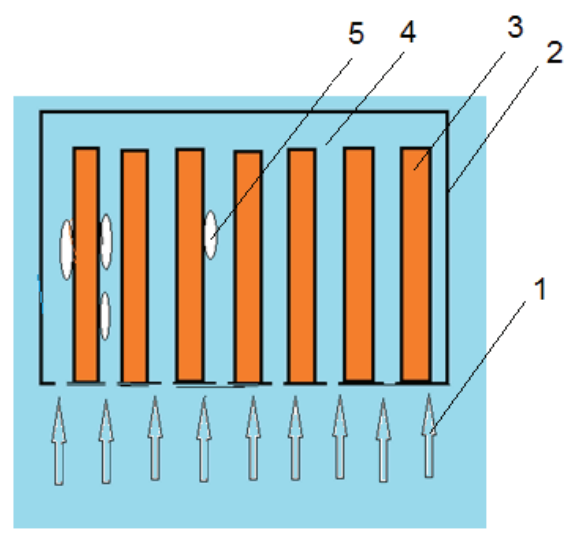

Fig. 5. A load of cylindrical steel parts prepared for batch quenching in the integral quench 36 " $\times 36$ " $\times 72$ " atmosphere furnace: 1 - water flow; 2 - container; 3 - cylindrical steel part; 4 - quenchant; 5 - local film boiling

The duration of the first step of IQ-2 process is calculated using generalized equations developed by author [10].

\section{Method of cooling time calculation}

During intensive quenching of steel parts in cold water and water salt solutions of optimal concentration film boiling is absent and main heat transfer modes are transient nucleate boiling and convection. To estimate duration of nucleate boiling process, the well-known equations were used $[3,4,9]$.

When initial austenitizing temperature is fixed at $850{ }^{\circ} \mathrm{C}$ and bath temperature at $20^{\circ} \mathrm{C}$, then results of calculations can be presented in simplified form (1) as [10, 11]:

$$
\tau_{\mathrm{nb}}=\Omega \mathrm{k}_{\mathrm{F}} \frac{\mathrm{D}^{2}}{\mathrm{a}}
$$

The value $\Omega$ is a function of convective Biot number and is provided in Fig. 6.

Some results of calculations are presented in Tables 1-3 and Fig. 6.

\section{Table 1}

Duration of transient nucleate boiling process for cylinders of different diameters when quenching in still water and convective heat transfer coefficient is equal to $776 \mathrm{~W} / \mathrm{m}^{2} \mathrm{~K}$

\begin{tabular}{ccccc}
\hline Diameter, $\mathbf{m m}$ & $\mathbf{B i}_{\text {conv }}$ & $\boldsymbol{\Omega}$ & $\mathbf{K}, \mathbf{~ m}^{\mathbf{2}}$ & $\boldsymbol{\tau}_{\mathbf{n b}}, \mathbf{s e c}$ \\
\hline 10 & 0.18 & 4.83 & $4.32 \times 10^{-6}$ & 3.87 \\
12.5 & 0.22 & 4.62 & $6.75 \times 10^{-6}$ & 5.78 \\
15 & 0.265 & 4.44 & $9.8 \times 10^{-6}$ & .8 \\
20 & 0.353 & 4.18 & $17.2 \times 10^{-6}$ & 13.3 \\
25 & 0.441 & 3.96 & $27 \times 10^{-6}$ & 19.8 \\
50 & 0.882 & 3.30 & $108.1 \times 10^{-6}$ & 66.1
\end{tabular}

Note: when $\mathrm{Bi} \rightarrow \infty$ during convection, the value $\Omega \rightarrow 0$ because no nucleate boiling at all in this case

As one can see from Fig. 6, the value $\Omega$ tends to zero when Biot number tends to infinity. It means that at high numbers of Biot criterion transient nucleate boiling disappear and direct convection starts [12]. That specific Biot number Bi can be evaluated as [12]:

$$
\mathrm{Bi}=\frac{2\left(\vartheta_{0}-\vartheta_{\mathrm{I}}\right)}{\vartheta_{\mathrm{I}}+\vartheta_{\mathrm{uh}}},
$$


where $\vartheta_{0}=T_{0}-T_{S} ; T_{0}-$ initial austenitizing temperature; $\vartheta_{I}=T_{I}-T_{S}, T_{I}$ - nucleate boiling start temperature; $T_{S}$ - saturation temperature; $\vartheta_{\text {II }}=T_{I I}-T_{S} ; T_{I I}$ - nucleate boiling finish temperature; $\mathrm{K}$ - Kondrat'ev form coefficient in $\mathrm{m}^{2}$; a - thermal diffusivity of material or liquid in $\mathrm{m}^{2} / \mathrm{s}$; $\lambda$ - thermal conductivity in $\mathrm{W} / \mathrm{mK}$.

Taken into account such approach, software has been developed for engineers to calculate cooling recipes when performing IQ-2 and IQ-3 processes $[2,3,5]$.

Table 2

Duration $\tau_{\mathrm{nb}}$ of transient nucleate boiling process for cylinders of different diameters $\mathrm{D}$ (when water flow is within $1.3-1.5 \mathrm{~m} / \mathrm{s}$ and convective heat transfer coefficient is equal to $4500 \mathrm{~W} / \mathrm{m}^{2} \mathrm{~K}$ )

\begin{tabular}{ccccc}
\hline Diameter, $\mathbf{m m}$ & $\mathbf{B i}_{\text {conv }}$ & $\boldsymbol{\Omega}$ & $\mathbf{K}, \mathbf{m}^{2}$ & \multicolumn{2}{c}{$\boldsymbol{\tau}_{\mathbf{n b}}, \mathbf{s e c}$} \\
\hline 10 & 1 & 3.08 & $4.32 \times 10^{-6}$ & 2.5 \\
12.5 & 1.28 & 2.88 & $6.75 \times 10^{-6}$ & 3.6 \\
15 & 1.53 & 2.70 & $9.8 \times 10^{-6}$ & 4.87 \\
20 & 2.04 & 2.42 & $17.2 \times 10^{-6}$ & 7.71 \\
25 & 2.56 & 2.21 & $27 \times 10^{-6}$ & 11.13 \\
30 & 3.07 & 2.08 & $39.9 \times 10^{-6}$ & 15 \\
40 & 4.09 & 1.76 & $69.17 \times 10^{-6}$ & 22.5 \\
50 & 5.11 & 1.55 & $108.1 \times 10^{-6}$ & 34.9 \\
80 & 8.18 & 1.102 & $276.7 \times 10^{-6}$ & 56.4
\end{tabular}

Table 3

Duration of transient nucleate boiling process for non-austenitized steel $\left(\lambda=44 \mathrm{~W} / \mathrm{mK}\right.$ and $\left.\mathrm{a}=10.8 \mathrm{~m}^{2} / \mathrm{s}\right)$ when water flow is within $1.3-1.5 \mathrm{~m} / \mathrm{s}$ and convective heat transfer coefficient is equal to $4500 \mathrm{~W} / \mathrm{m}^{2} \mathrm{~K}$

\begin{tabular}{ccccc}
\hline Diameter, $\mathbf{m m}$ & $\mathbf{B i}_{\text {conv }}$ & $\boldsymbol{\Omega}$ & $\mathbf{K}, \mathbf{m}^{2}$ & \multicolumn{2}{c}{$\boldsymbol{\tau}_{\mathbf{n b}}, \mathbf{s e c}$} \\
\hline 10 & 0.51 & 3.73 & $4.32 \times 10^{-6}$ & 1.5 \\
12.5 & 0.64 & 3.50 & $6.75 \times 10^{-6}$ & 2.17 \\
15 & 0.77 & 3.36 & $9.8 \times 10^{-6}$ & 3.03 \\
20 & 1.02 & 3.09 & $17.2 \times 10^{-6}$ & 4.88 \\
25 & 1.28 & 2.87 & $27 \times 10^{-6}$ & 7.12 \\
50 & 2.55 & 2.21 & $108.1 \times 10^{-6}$ & 22
\end{tabular}

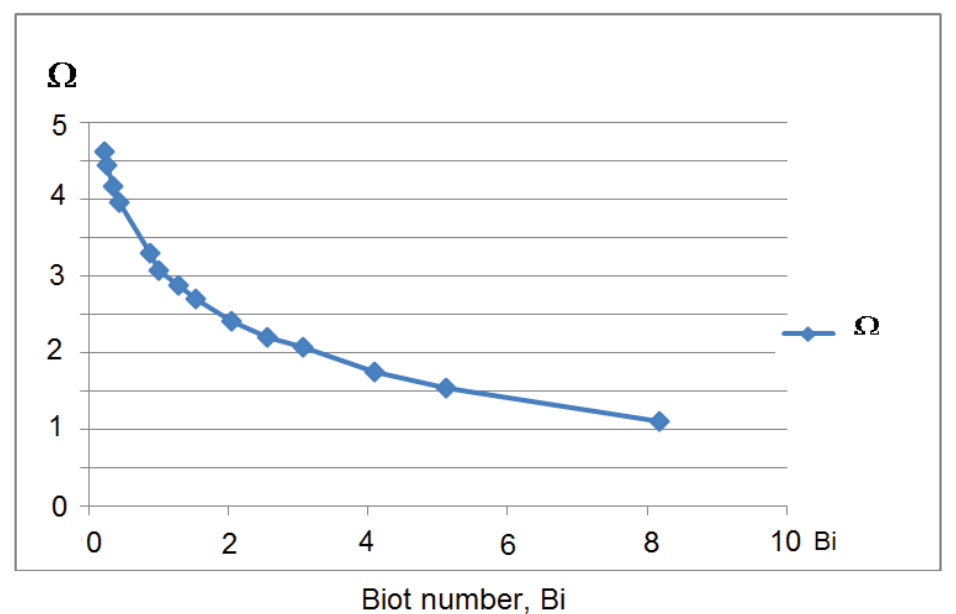

Fig. 6. Value $\Omega$ versus convective Biot number for cylindrical forms of steel parts 


\section{Hydrodynamics wave emitters}

When quenching loads consisting of large number of parts (especially relatively thin parts), a local film boiling process takes place at the beginning of the quench even in the IQ water tanks with a vigorous agitation of the water salt solution. It has been revealed by authors [6] that local film boiling is the main reason for the excessive part distortion (Fig. 5). For gear products, a "double" distortion occurs some times when the local film boiling takes place between two teeth of the gear. That is why, the author of the current paper suggested using oscillatory waves produced by a hydrodynamic emitter for destroying local large film bubbles by a resonance effect in addition to the quenchant agitation during IQ-2 process [1].

A first prototype of the hydrodynamics wave emitter was built and evaluated in 1978 [13]. The design of hydrodynamic emitter is discussed in the book [2] and its sketch is presented in Fig. 7. The emitter was used for generating ultrasound oscillations during quenching of steel samples in mineral oil. However, ultrasound oscillations could not provide a resonance effect for the film boiling because of the significant difference of the film boiling frequencies and ultrasound frequency. According to authors [14], the film boiling frequencies are within the range of 500 to $1500 \mathrm{~Hz}$, while the ultrasound devices operate with frequencies from $20 \mathrm{kHz}$ up to several gigahertzes. For calculating a frequency that provides a resonance effect, equation (9) can be used [1]:

$$
\mathrm{f}_{\mathrm{Hz}}=\frac{n \mathrm{~V}_{\mathrm{C}}}{\pi \mathrm{D}},
$$

where $\mathrm{f}_{\mathrm{Hz}}$ - a resonance frequency for the film boiling process in $\mathrm{Hz} ; \mathrm{n}-\mathrm{a}$ number of restrictions or openings on the round nozzle required for providing a resonance wave (Fig. 7); $\mathrm{V}_{\mathrm{C}}-$ a circulated water flow velocity in $\mathrm{m} / \mathrm{s}$; D - a diameter of the nozzle in $\mathrm{m}$.

Note, that each restriction or opening generates packages of waves. The primary one is calculated by equation (3).

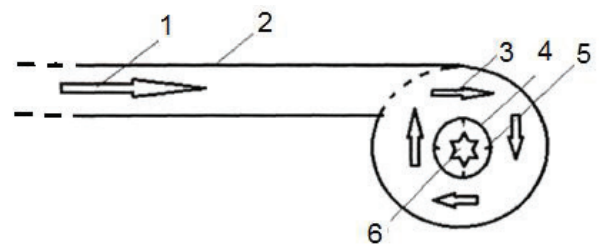

Fig. 7. Schematic of the hydrodynamics emmitter generating waves in liquid with the frequency equal to the oscilating frequency of local film boiling: 1 - a water flow rate provided by the pump; 2 - a tube, 3 - a circulted water stream; 4 - a generator of waves in liquid; 5 - a regulator of the wave frequency;

6 - a water flow combined with the generated waves and directed to load being quenched [1]

Designing of guidelines for manufacturing of appropriate hydrodynamics emmiters should be further developed prior to commercializing of this method.

\section{Discussion}

Nobody could believe that steel parts don't crack when quenching with a very high cooling rate, while the part distortion is lower and mechanical properties and performance characteristics are superior compared to conventional quenching in oil. It was in contradiction with the existing theory which underlined "...one should never allow high cooling rate within the martensitic range" if he wish to prevent crack formation and decrease distortion. Fundamental work in this field has been fulfilled by IQ Technologies Inc. [7, 8]. Intensive Technologies Ltd, Kyiv, Ukraine and IQ Technologies Inc., Akron, Ohio, have been cooperating since 2000 and as a result the mentioned above idea was supported by industry and accurate laboratory experiments. Distortion was decreased more than three times as compared with oil quenching. It can be further decreased by the use of hydrodynamic emitters to be installed in quench tanks and also by correct calculation the duration of the first step of intensive quenching using eq. (1) which is true when local film boiling 
in batch quenching is completely eliminated. Further joint investigations will focus on evaluation frequencies of local film boiling processes and modifying and optimizing hydrodynamic emitters.

Intensive Technologies Ltd. (ITL) of Kyiv, Ukraine has proposed an idea of using hydrodynamics wave emmiters for producing a resonance effect that immediately destroys local film boiling. However, implementing of this approach requires accurate data on frequences and intensity of film and local film boiling processes. ITL will develop such data. Also, a very useful information on this subject is available in published papers [15-22]. However, local film boiling processes are investigated not deeply and widely enough. Further investigations in this field are needed and are very important for providing resonance effect. More information on a nonlinear wave mechanics and technologies one can find in books [23-27]. It should be noted that steel part distortion problem was mainly solved by using a slow cooling media like water polymer solution of high concentration. It was shown later that IQ processes decrease the part distrotion if cooling is very fast and uniform [28-30]. It means that hydrodynamics emitters for generating resonance waves have a great future in eliminating local film boiling and decreasing part distortion.

\section{Conclusions}

1. A method for improving IQ-2 processes for minimizing part distrotion is proposed. The method is based on the elimination of the local film boiling process by providing waves in liquids having a resonance frequency that destroys local vaper films. The method is patented in Ukraine [1].

2. The proposed method allows using any apparatus generating oscillatory waves in liquid media. There ia a need in further development of special hydrodynamics emmiters generating waves with the controlled frequency.

3. The proposed method is more effective as compared with the original IQ-2 process since it minimizies the air entrain by tank propellers, there is no hydrodynamics resistance for oscillatory waves, it uses less energy and makes the cooling process shorter due to the elimination of local and full film boiling processes.

4. The proposed method, along with the original version of the IQ-2 process, can be used also in conventional oil and polymer quench tanks to decrease significantly distortion of quenched steel parts by eliminating local film boiling.

5. To use the proposed method widely in practice, a database on the frequency and intensity of local film boiling for different quenchants and different load configurations should be available for engineers.

6. The resonance waves destroying local film boiling may affect convective heat transfer coefficients. This possible effect should be carefully investigated.

\section{Acknowledgement}

Author is greatful to Dr. M. A. Aronov, CEO of IQ Technologies Inc., Akron, Ohio, USA, for discussing of the proposed idea and for careful ediding of the paper, and providing pictures for Fig. 3, 4 .

\section{References}

[1] Kobasko, N. I. (2015). Intensive Hardening Method for Metal Components, MPK: C21D 1/63 (2006.01), C21D 1/56 (2006.01), C21D 1/78 (2006.01), C21D 1/18 (2006.01), Ukrainian Patent, UA № 109572, declareted: 07.10.2013; published: 10.09.2015, Bul. 17/2015.

[2] Kobasko, N. I. (1980). Steel Quenching in Liquid Media Under Pressure. Kyiv: Naukova Dumka, 206.

[3] Kobasko, N. I. (2000). A Method of Hardening of Alloy Steels. MPK: C21D 1/18, Ukrainian Patent, UA № 27059, declareted: 17.02.1995; published: 28.02.2000, Bul. 1/2000.

[4] Liščić, B., Tensi, H. M., Luty, W. (Eds.). (1992). Theory and Technology of Quenching. doi: 10.1007/978-3-662-01596-4

[5] Dossett, J. I., Totten, G. E. (Eds.) (2013). ASM Handbook Volume 4A Steel Heat Treating Fundamentals and Processes. USA, 768.

[6] Kobasko, N. I., Aronov, M. A., Ferguson, B. L., Li, Z. (2012). Local Film Boiling and Its Impact on Distortion of Spur Gears During Batch Quenching. Materials Performance and Characterization, 1 (1), 104533. doi: $10.1520 / \mathrm{mpc} 104533$ 
[7] Aronov, A., Kobasko, N., Powell, J., Andreski, B., O’Rourke, B., (2014). Intensive Quenching Processes: Basic Principles, Applications, and Commercialization. Proc. of European Conference on Heat Treatment and $21^{\text {st }}$ IFHTSE Congress. Germany, Munich, 267-274.

[8] Aronov, A., Kobasko, N., Powell, J., Kim, H., O’Rourke, B., Andreski, B. (2015). Application of Intensive Quenching Process for Steel Mill Rolls Made of Ductile Iron, The MS\&T 2015, Material Science and Technology Conference and Exhibition, 4-8.

[9] Liscic, B., Tensi, H., Canale, L., Totten, G. (Eds.) (2010). Quenching Theory and Technology, Second Edition, 709. doi: 10.1201/9781420009163

[10] Kobasko, N. I. (2009). Transient Nucleate Boiling as a Law of Nature and a Basis for Designing of IQ Technologies. 7th IASME/WSEAS International Conference on Heat Transfer, Thermal Engineering and environment (THE'09), 67-75.

[11] Tolubinsky, V. I. (1980). Heat Transfer at Boiling. Kyiv: Naukova Dumka, 315.

[12] Kobasko, N. I. (2002). Quenching Apparatus and Method for Hardening Steel Parts, U.S. № US6364974 B1. declareted: 18.05.1999; published: 2.05.2002, Bul. US 09/551, 082.

[13] Zhelokhovtseva, R. K., Logachev, A. I. (1978). Effect of ultrasound on cooling characteristic of mineral oil. Union Conference on Increasing Service Life of Machine Components by Technological Processes, Frunze, 28-29.

[14] Moskalenko, A. A., Kobasko, N. I., Tolmacheva, O. V., Totten, G. E., Webster, G. M. (1996). Quenchants characterization by acoustical noise analysis of cooling properties of aqueous poly (alkylene glycol) polymer quenchants. 2-nd International Conference on Quenching and Control of the Distortion.

[15] Dhir, V. K. (1998). Boiling heat transfer. Annual Review of Fluid Mechanics, 30 (1), 365-401. doi: 10.1146/annurev.fluid.30.1.365

[16] Yagov, V. V. (2007). Nucleate boiling heat transfer: possibilities and limitations of theoretical analysis. Heat and Mass Transfer, 45 (7), 881-892. doi: 10.1007/s00231-007-0253-8

[17] Labuntsov, D. A. (2000). Physical Fundamentals of Power Engineering, Selected Works on Heat Transfer, Hydrodynamics and Thermodynamics. Moscow: MPEI.

[18] Prezelj, Ju., Ravnik, F., Grum, J., Čudina, M. (2007). Sound signature of steel hardening process. 3rd Congress of the Alps Adria Acoustics Association. Austria: Graz.

[19] Nakoryakov, V. E., Pokusaev, B. G., Pribaturin, N. A., Shreiber, I. R. (1984). Shock waves in boiling liquids. International Communications in Heat and Mass Transfer, 11 (1), 55-62. doi:10.1016/0735-1933(84)90030-7

[20] Ravnik, F., Grum, J., Prabhu, N., Kobasko, N., Dean, S. W. (2011). Heat Transfer Stages Recognition by Boiling Acoustic During Quenching. Journal of ASTM International, 8 (1), 103386. doi: 10.1520/jai103386

[21] Grum, J., Božič, S. (2003). Acoustic Emission During Quenching of 42CrMo4 Steel. Fourth International Conference on Quenching and the Control of Distortion.

[22] Dorofeev, B. M., Volkova, V. I. (2005). An Acoustic Method of Investigation of the Process of Boiling. High Temperature, 43 (4), 620-627. doi: 10.1007/s10740-005-0104-6

[23] Ganiev, R. F., Ukrainskiy, L. E. (2012). Nonlinear Wave Mechanics and Technologies- Wave and Oscillatory Phenomena on the Basis of High Technologies. USA: Begell House, 527.

[24] Ukrainskiy, L. E., (2003). Dynamic behavior of gas inclusions in the viscous liquid. Moscow: Fizmatlit, 220.

[25] Zhang, J., Zhao, W., Wei, Z., Tang, Y., Lu, B. (2007). Numerical and experimental study on hydraulic performance of emitters with arc labyrinth channels. Computers and Electronics in Agriculture, 56 (2), 120-129. doi: 10.1016/j.compag.2007.01.007

[26] Qingsong, W., Yusheng, S., Gang, L., Wenchu, D., Shuhuai, H. (2006). Study of hydraulic performance of the eddy channel for drip emitters. Irrigation and Drainage, 55 (1), 61-72. doi:10.1002/ird.216

[27] Li, Y., Feng, J. (2014). Progress in measurement hydrodynamics characteristics in drip irrigation emitters, Journal of Drainage and Irrigation Machinery Engineering, 32 (1), 86-92. doi: 10.3969/j.issn.16748530.13.0212

[28] Totten, G., Howes, M., Inoue, T. (Eds.) (2002). Handbook of Residual Stress and Deformation of Steel. Ohio: ASM International, 499.

[29] Xie, L., Funatani, K., Totten, G. (Eds.) (2004). Handbook of Metallurgical Process Design. Materials Engineering. New York: Marcel Dekker, 966. doi: 10.1201/9780203970928

[30] Totten, G. E. (Ed.) (2007). Steel Heat Treatment Handbook. $2^{\text {nd }}$ Edition. New York: CRC Press, 713. 